\title{
A Triade Religiosidade, Gênero e Direitos Humanos: diálogo com professoras membros da Congregação Cristã do Brasil (CCB)
}

\author{
The trip religiousity, gender and human rights: dialogue \\ with teachers members of the Christian Congregation of
} Basil (CCB)

\author{
Marcelo Máximo Purificação ${ }^{1}$ \\ Elisângela Maura Catarino ${ }^{2}$ \\ Maria Luzia da Silva Santana ${ }^{3}$ \\ Filomena Teixeira ${ }^{4}$
}

\section{Resumo}

As transformações decorrentes da luta pelo respeito à diversidade, incluindo as questões de gênero e a tolerância religiosa, instigou esse diálogo acerca da construção da identidade de professoras pentecostais da Congregação Cristã do Brasil (CCB), a partir da tríade religiosidade, gênero e direitos humanos. Esse artigo tem o objetivo de refletir sobre os significados das práticas educativas de professoras que são membros da Congregação Cristã do Brasil (CCB) educativas essas quando envolvem temas que perpassam a religiosidade. Essa pesquisa qualitativa, contou com 6 (seis) professoras partícipes da Congregação Cristã do Brasil que, escolhidas aleatoriamente, responderam aos questionamentos e, ao mesmo tempo, apresentaram o universo pentecostal mediante correio eletrônico. A análise dos resultados foi ancorada pelo aporte teórico acerca dos direitos humanos, interculturalidade, religiosidade e gênero que possibilitou uma leitura interpretativa dos significados expressos pelas participantes, que relataram a dificuldade em trabalhar a diversidade em sala de aula, principalmente quando estão em voga questões ligadas às religiões afro, sexualidade, drogas e outros temas

\footnotetext{
${ }^{1}$ Pós-Doutor em Educação pela Universidade de Coimbra (PO). Doutor em Ciências da Religião pela PUC-Goiás. Professor Titular no Centro Universitário de Mineiros - UNIFIMES/GO. E-mail: maximo@unifimes.edu.br.

2 Pós-Doutora em Educação pela Escola Superior de Educação de Coimbra -ESEC. Doutora em Ciências da Religião pela PUCGoiás. Professora Adjunta no Centro Universitário de Mineiros UNIFIMES/GO. E-mail: maura@unifimes.edu.br.

${ }^{3}$ Doutora e Mestra em Psicologia pela Universidade Católica de Brasília. Professora Assistente DE - Universidade Federal do Mato Grosso do Sul UFMS. E-mail: santanapsi@gmail.com.

${ }^{4}$ Doutora em Didática pela Universidade de Aveiro - Portugal. Professora Adjunta da escola Superior de Educação de Coimbra ESEC-Portugal, Email: filomena.tx@gmail.com.
} 
Religare, ISSN: 19826605, v.15, n.2, dezembro de 2018, p.670-686.

transversais. Assim, é importante discutirmos essas questões para consolidação da inclusão e tolerância às diferenças, calcadas no respeito e na dignidade da pessoa humana.

Palavras-chave: Direitos humanos; Gênero; Professoras; Religiosidade.

\section{Abstract}

The transformations stemming from the struggle for respect for diversity, including gender issues and religious tolerance, instigated this dialogue on the construction of the identity of Pentecostal teachers of the Christian Congregation of Brasil (CCB), based on the triad religiosity, gender and human rights. This article aims to reflect on the meanings of teachers who are members of the Brazilian Christian Congregation (CCB) about their educational practices when they involve themes that pervade religiosity. This qualitative research had six (6) professors participating in the Christian Congregation of Brazil, who werechosen at random, answered the questions and at the same time presented the Pentecostal universe by electronic mail. The analysis of the results was anchored by the theoretical contribution on human rights, interculturality, religiosity and gender that made possible an interpretative reading of the meanings expressed by the participants. They have reported on the difficulty of working with diversity in the classroom, especially when issues related to Afro religions, sexuality, drugs and other cross-cutting themes are in vogue. Thus, it is important to be open to the inclusion and respect of difference, based on the respect and dignity of the human person.

Keywords: Human rights; Genre; Teachers; Religiosity.

\section{Introdução}

A sociedade brasileira é marcada pela complexidade e fluidez dos tempos modernos, cenário que colabora para a construção identitária plural de indivíduos, marcada pelas diferenças de gênero, hábitos, língua e religião,

presentes no contexto escolar.Zanatta (2013) discutindo sobre diversidade religiosa e sua importância na sala de aula, salienta que a questão religiosa aparece relacionada às grandes guerras e inúmeros conflitos sociais, exerce 
Religare, ISSN: 19826605, v.15, n.2, dezembro de 2018, p.670-686.

intervenção sobre o comportamento social da maioria das pessoas e tem estreita relação com a vida familiar, escolar, social e política.

Quanto à interface entre religião e escola, não há um aprofundamento histórico dessa discussão ou "um olhar atento às características culturais dos professores e dos alunos brasileiros, nem à sua subjetiva religiosidade" (VALENTE, 2018, p. 108). A religião no contexto escolar se faz presente através de diferentes maneiras, até mesmo mediante a religiosidade individual do docente (VALENTE, 2018).

Cabe pontuar a diferença entre religião e religiosidade. A religião, de caráter institucional, institui categorias de pensamento e de julgamento, indica maneiras de ação e uma única "verdade", absoluta e inquestionável, que se situa além do material, natural, concreto e finito (VALENTE, 2017).

A religião é uma forma cultural, isto é, produto histórico-social da religiosidade. Ela formaliza e consagra os laços sociais, reforçando-os e (re)ligando os indivíduos. Além disso, ela organiza a vida coletiva para dar segurança na manutenção das relações sociais, com base na proposição de um modo de ser e em uma ordenação ou categorização do mundo e da experiência humana. Pode-se dizer que a religião é o aspecto estrutural da religiosidade (VALENTE, 2018, p. 120).

As religiões são tidas como elemento de civilização ao criar estruturas que possibilitariam a vida em grupo, como as interdições, os tabus, os mitos e leis; contudo, ao longo do processo civilizatório, houve transformações de ideais, valores, normas e de conhecimento em permanente construção (JUNQUEIRA; RODRIGUES, 2014).

Nota-se que o saber religioso contém elementos simbólicos que influenciam a sociedade que o caracteriza e estrutura, sendo referenciais usados pelas pessoas e grupos sociais para (re) construir sua existência e dar respostas às distintas situações e desafios do cotidiano. Porém, historicamente, o convívio entre pessoas com crenças e convicções religiosas 
Religare, ISSN: 19826605, v.15, n.2, dezembro de 2018, p.670-686.

diversas tem sido caracterizado por "conflitos e imposições, negações e invisibilizações, preconceitos e discriminações, muitas vezes legitimadas por representações sociais equivocadas, rotuladoras e exotizadoras da (des) crença do Outro" (CECCHETTI; OLIVEIRA, 2015, p.185).

A construção de um ambiente escolar tolerante quanto à diversidade religiosa requer o conhecimento das religiões como fenômeno sempre presente nas diferentes culturas, nos diversos percursos históricos e que contêm crenças com características próprias de sua civilização, que motive a sintaxe de um convívio afetuoso, reflexivo a respeito das diferenças religiosas, com o resgate da proposta ética e moral (MILANI, 2013). Esse olhar para as questões religiosas na educação encontra eco no Plano Nacional de Educação em Direitos Humanos (PNEDH) ao reconhecer que a educação contribui para "exercitar o respeito, a tolerância, a promoção e a valorização das diversidades" (BRASIL, 2006).

9. fomentar a inclusão, no currículo escolar, das temáticas relativas a gênero, identidade de gênero, raça e etnia, religião, orientação sexual, pessoas com deficiências, entre outros, bem como todas as formas dediscriminação e violações de direitos, assegurando a formação continuada dos(as) trabalhadores(as) da educação para lidar criticamente com esses temas (idem, p. 24).

18. desenvolver políticas estratégicas de ação afirmativa nas IES que possibilitem a inclusão, o acesso e a permanência de pessoas com deficiência e aquelas alvo de discriminação por motivo de gênero, de orientação sexual e religiosa, entre outros e seguimentos geracionais e étnico-raciais (idem, p. 29).

Candau (2008) discutindo algumas questões relativas à importância da(s) cultura(s) nas sociedades atuais, situa a relevância do discurso dos direitos humanos e da perspectiva intercultural do multiculturalismo nesse contexto, assinalando alguns desafios considerados relevantes para trabalhar as relações entre educação intercultural e direitos humanos, que busque articular a igualdade e diferença, no sentido de trabalhar a igualdade na 
Religare, ISSN: 19826605, v.15, n.2, dezembro de 2018, p.670-686.

diferença, que objetive superar a desigualdade e, simultaneamente, reconhecer as diferenças culturais, o que implica a ação voltada aos direitos humanos, o que requer o exercício do diálogo intercultural (CANDAU, 2008).

É notório que cabe à educação, especificamente às instituições educativas, favorecer a formação cidadã, que potencialize as habilidades, capacidades e atitudes para o respeito e convívio com a diferença, incluindo a diversidade religiosa, de identidade, de gênero e étnica. No que se refere à educação no viés do respeito à diversidade religiosa, estás e constituindo como um meio para o término de conflitos religiosos, violações dos direitos humanos e desrespeito à liberdade de pensamento, consciência, religião ou qualquer convicção. Mas, para promover a liberdade religiosa e os direitos humanos, é necessário o desenvolvimento de práticas pedagógico-didáticas que despertem para o exercício da sensibilidade diante de qualquer discriminação religiosa no trato cotidiano, no respeito à identidade na alteridade, no encontro com as diferentes expressões religiosas, ateias ou agnósticas (CECCHETTI; OLIVEIRA, 2015, p.189).

A promoção dos direitos humanos implica em reconhecer a diversidade cultural, sendo que a construção de práticas educativas pautadas na educação intercultural contribuirá para isso, haja vista sua proposta de convívio em sociedades plurais, o que "requer um aprendizado para a convivência na pluralidade e um exercício permanente de respeito à dignidade e os direitos humanos" (REZENDE JR, 2013, p.4). A perspectiva intercultural da educação pressupõe o reconhecimento do outro, o diálogo entre os distintos grupos socioculturais, visando" à construção de uma sociedade democrática, plural, humana, que articule políticas de igualdade com políticas de identidade" (CANDAU, 2008, p.54).

A análise das questões históricas ligadas à religião denuncia que, na trajetória institucionalizada das grandes religiões, constata-se que as lideranças femininas foram inferiorizadas, reforçando o imaginário social de que a mulher religiosa deve estar sempre a serviço da superioridade religiosa 
Religare, ISSN: 19826605, v.15, n.2, dezembro de 2018, p.670-686.

masculina. Com o advento da modernidade, das lutas e consequentemente das conquistas pelo direito de igualdade de tratamento entre os gêneros, em vários segmentos constatam-se avanços significativos. No entanto, em nosso cotidiano ainda convivemos com as relações de poder quanto ao gênero que perpassam vários setores e segmentos da sociedade contemporânea, reforçando o preconceito e estereótipos, firmando um modelo de contrato sexual nas relações sociais em que o masculino é historicamente reconhecido como normativo (SCOTT, 1990).

Percebe-se a importância de discursos de gêneros no contexto religioso, ou que perpassem a "religião" - que é vista como uma construção sociocultural, interlaçada em transformações sociais, que culminam em relações de poder, de classes, gênero, raça/etnia (SOUZA, 2006). Por isso, qualquer estudo que navegue por esse oceano de trocas simbólicas e de jogos de interesses deve observar os "territórios" ${ }^{5}$ envolvidos e seus contextos, seus significados para o capital cultural de indivíduos que, de forma (in)direta, contribuem para a reconstrução de hábitos sociais.

As transformações decorrentes da luta pelo respeito à diversidade, incluindo as questões de gênero e a tolerância religiosa, instigaram esse diálogo acerca da construção da identidade de professoras pentecostais da Congregação Cristã do Brasil (CCB), a partir da tríade religiosidade, gênero e direitos humanos. Assim, este artigo tem o objetivo de refletir sobre os significados das práticas educativas de professoras que são membros da Congregação Cristã do Brasil (CCB) quando essas envolvem temas que perpassam a religiosidade.

\footnotetext{
${ }^{5}$ Neste contexto, o termo "território" é compreendido como os espaços e grupos sociais.
} 
Religare, ISSN: 19826605, v.15, n.2, dezembro de 2018, p.670-686.

\section{Metodologia}

Este estudo põe em tela uma questão singular, qual seja, a tríade religiosidade, gênero e direitos humanos propondo um diálogo através da pesquisa qualitativa. Para Minayo (2001, p. 22) essa modalidade de pesquisa estuda um nível de fenômeno não quantificado, “ou seja, ela trabalha com o universo de significados, motivos, aspirações, crenças, valores e atitudes, o que corresponde a um espaço mais profundo das relações, dos processos e dos fenômenos que não podem ser reduzidos ao operacionalização de variáveis"(MINAYO, 2001, p. 22)

Este estudo aborda as questões de gênero, buscando colocar em diálogo os direitos humanos e a religiosidade, tendo como recorte o pentecostalismo. Para isso, contou com 6 (seis) professoras partícipes da Congregação Cristã do Brasil, escolhidas aleatoriamente da mesma região [sudoeste de Goiás], porém de cidades diferentes.

As participantes responderam aos questionamentos e, ao mesmo tempo, apresentaram o universo pentecostal mediante uma entrevista via correio eletrônico. A sistematização e análise dos resultados dessa pesquisa, utilizou o aporte teórico acerca dos direitos humanos, interculturalidade, religiosidade e gênero, que ancorou teoricamente a discussão do relato e as explicitações das participantes, possibilitando uma leitura interpretativa dos significados expressos por elas.

\section{Desenvolvimento - Educação e Religiosidade}

A religiosidade possui uma dimensão subjetiva da identidade dos educadores, “atravessa a prática docente de forma única e compõe, em conjunto com outros elementos, a totalidade das disposições culturais do 
Religare, ISSN: 19826605, v.15, n.2, dezembro de 2018, p.670-686.

indivíduo; é um elemento simbólico interiorizado e inconsciente, muitas vezes" (VALENTE, 2018, p. 121). Assim, de maneira direta ou indireta, a religiosidade tem implicações nas ações pedagógicas em sala de aula e na aprendizagem dos estudantes (VALENTE, 2018).

Nesse sentido, é relevante discutir a identidade de educadoras da Congregação Cristã do Brasil (CCB), considerando a tríade religiosidade, gênero e direitos humanos; para tal, faz-se necessário conhecer a trajetória histórico-social do pentecostalismo no território brasileiro e consequentemente da (CCB), seu marco inicial, para compreender, a partir de uma perspectiva histórica e multidisciplinar, as representações sociais e seus liames no contexto cultural, educacional e religioso.

As mulheres professoras entrevistadas (da CCB), que estão em sala de aula nas redes pública ou privada de ensino, pontuaram certa dificuldade quanto ao ideário religioso institucionalizado. Mesmo com a Constituição Federal de 1988 sinalizando que "todos são iguais perante a lei, sem distinção de qualquer natureza", elas têm dificuldade de trabalhar sem proselitismo. Professoras com perfis religiosos e práticas dogmáticas, muitas vezes inconscientemente, têm dificuldade para trabalhar a diversidade de forma a respeitar as diferenças étnicas e religiosas no âmbito educativo. Frente a isso, a escola passa a ser um espaço fortemente marcado pela "violência simbólica" ${ }^{6}$, requerendo reflexões e fazeres educativos que favoreçam

[...] não somente o respeito aos diferentes sagrados, mas sua capacidade de potencializar sentimentos de fé em uma atmosfera de cultura não uniforme. A aproximação de diversidades potencializa espaços de acolhida, encontros com a outra e o outro em sua alteridade, com o olhar da outra e do outro, sensibilizado ao diferente de mim, que fala a partir de sua singularidade, em sua especificidade de local de cultura. Contudo, ainda precisamos aprender a viver na diversidade. Discriminamos nossos semelhantes porque estes pensam de forma diferente, fazem suas preces de maneira diferente, chamam a divindade de um nome diferente, ou não tem

${ }^{6}$ Concepção de Pierre Bourdieu. 
Religare, ISSN: 19826605, v.15, n.2, dezembro de 2018, p.670-686.

algum vínculo religioso. Discriminamos, ofendemos, praticamos atos de violência contra nosso semelhante, porque não sabemos conviver com a diversidade e respeitar as diferenças (REZENDE JR, 2013, p. 9).

Quando questionamos a uma das colaboradoras da pesquisa, se ela se sente confortável para trabalhar as questões afro-brasileiras, o que agora é uma exigência curricular (Cf. Lei 10639/2003), ela respondeu:

[...] não me sinto confortável, nem preparada para tal missão. Falar sobre a historicidade dos negros no Brasil não é tão difícil. O problema é adentrar no terreno sagrado da cultura afro. Não me sinto preparada para discutir com meus alunos sobre a Umbanda e o Candomblé. Eles logo perceberiam que ali não seria eu. Só que é difícil para mim trabalhar numa escola pública e laica, com essa limitação (respondente 1 da entrevista para esta pesquisa).

Outro tabu para as professoras entrevistadas da CCB é trabalhar com as questões transversais que os $\mathrm{PCN}^{\prime}$ 's sugerem, como sexualidade. Nossa segunda colaboradora assim responde: "Hoje as salas de aula são homogêneas, trabalhamos essas temáticas simultaneamente com meninas e meninos no mesmo espaço. Isso é difícil, é complicado. A última vez que estive diante de uma situação como essa, tive que pagar uma professora substituta para ministrar a temática para mim". Tal declaração corrobora a ideia de que "a religiosidade não só atravessa a prática docente, de acordo com a configuração de crenças de cada professor, mas também possui consequências para a socialização das crianças que frequentam o espaço escolar" o que reitera "a necessidade de mais debates e trocas entre pesquisadores nacionais e estrangeiros"'(VALENTE, 2018, p. 123).

A discriminação entre seres humanos por motivos de religião ou de convicções constitui uma ofensa à dignidade humana e deve ser condenada como uma violação dos Direitos Humanos e das liberdades fundamentais, proclamados na Declaração Universal dos Direitos Humanos [...] e um obstáculo para as relações amistosas e pacíficas entre as nações ((REZENDE JR, 2013, p. 21).

Uma terceira colaboradora disse que tem medo até de falar determinados assuntos na escola e em sala de aula, pois agora tudo é preconceito, é racismo. Diz ela: “Esses dias estava lendo uma matéria da Revista Fórum que uma professora evangélica tinha sido - denunciada por 
Religare, ISSN: 19826605, v.15, n.2, dezembro de 2018, p.670-686.

racismo e preconceito religioso contra criança: "preta do diabo", "endemoniada", "satanás"7 - acho tudo isso fantasioso, midiático. Tenho minhas concepções religiosas, mas jamais chegaria a esse ponto". Ademais aponta a importância da busca pelo diálogo inter-religioso, a valorização do ser humano como sujeito de sua própria história e de suas escolhas, independente de pertença religiosa. É fundamental que o diálogo entre as religiões em defesa dos Direitos Humanos, no Brasil e no mundo seja sempre ampliado (REZENDE JR, 2013, p. 17).

\subsection{Questões de gênero e religiosidade de professoras}

As religiões, enquanto organizações, são marcadas por uma visão fundamentalista que se materializa na limitação de espaços/ações das mulheres nesses contextos. Embora sabendo do seu papel e de suas contribuições históricas no decorrer do desenvolvimento da humanidade, percebe-se as religiões como instituições diversas e conflitantes. Nesse cenário de complexidade, a teologia feminista vem ganhando cada vez mais espaços. Cobra-se a equiparação de tratamento entre os sexos nas estruturas organizacionais das religiões, mas para alguns, trata-se de um ideal utópico, uma vez que já está arraigado em hábitos milenários.

No cenário atual, a sociedade e o Estado têm novas configurações, dentre as quais a necessidade de repensar o papel das mulheres nesses espaços. Tivemos pequenos, porém significativos, avanços em vários cenários sociais, onde as mulheres passaram a ocupar espaços até então vistos como masculinos. No entanto, no cenário religioso ainda continuamos estagnados,

\footnotetext{
Disponível em http://www.revistaforum.com.br/2014/11/28/professora-evangelica-edenunciada-por-racismo-e-preconceito-religioso-contra-crianca-preta-diabo-endemoniadasatanas/ acessada em 12/01/2017.
} 
Religare, ISSN: 19826605, v.15, n.2, dezembro de 2018, p.670-686.

a mulher continua ocupando espaços minoritários, numa posição de servidão e inferioridade.

Percebe-se que, mesmo em posições hierárquicas inferiores, as mulheres da Congregação Cristã do Brasil, desenvolvem importantes ações como agentes de execução/confirmação dos ideais institucionais, principalmente a perpetuação da formação educacional moral do indivíduo. Para início do diálogo acerca das questões de gênero no universo das religiões, foi proposto o seguinte questionamento: como mulheres e homens são tratados nas religiões?

Tomando por base algumas fundamentações religiosas, percebe-se uma posição verticalizada na relação homem e mulher, na qual a mulher ocupa espaços inferiores aos do homem.

A primeira questão discutida foi: quem é a mulher na Congregação Cristã do Brasil? Como resposta tivemos:

“[...] a mulher na CCB é um ser atuante, tem espaço no 'ministério da música' como organista durante as celebrações, pode fazer parte do ministério das 'irmãs da piedade' que visitam as famílias, no intuito de atendê-las socialmente, as funções principais são dos homens, e nós entendemos isso, pois é um costume cultural" (Cf. entrevistada 4).

É histórico o desequilíbrio de direitos e de espaços que liga gênero e religião. Rey (2003) explica que: "parte do pensamento ocidental onde se edifica o pensamento de [que o homem é] um sujeito ideal, cuja construção interlaça as esferas da ética, política e religião. Um sujeito privilegiado por seus aspectos biológicos, a viver tudo aquilo para o qual fora criado, sujeito capaz de dominar o mundo e a si mesmo".

Na linha dos nossos questionamentos perguntamos: qual a simbologia do véu? A resposta dada pela colaboradora 2, foi: "se você pegar a doutrina da CCB, ou ler nas páginas eletrônicas de nosso movimento, encontrará a 
Religare, ISSN: 19826605, v.15, n.2, dezembro de 2018, p.670-686.

resposta. Pois essa é uma das indagações que mais ouvimos" (Cf. entrevistada 2). Esse relato foi endossado pela descrição:

\begin{abstract}
"Toda mulher que ora ou profetiza com a cabeça descoberta, desonra sua própria cabeça"; dessa forma, quando a mulher não se cobre com o véu, estará proclamando através desse ato exterior que está desonrando o homem a quem está sujeita "porque a mulher é a glória do varão" (v.7); porque foi tirada do homem e criada para o homem (Gn 2:18-24). A glória da mulher é o cabelo dado como véu (v.14). ${ }^{8}$
\end{abstract}

A resposta que a entrevistada deu para a questão deixa explícita uma naturalidade na prática do uso do véu. No entanto, essa representação pode ser interpretada como o espaço atribuído à mulher de subordinação, limitação de suas funções nesse contexto religioso.

Compreendo o sujeito a partir da subjetividade ${ }^{9}$ defendida por Rey (2003), percebe-se que “o princípio racional das crenças, que esteticamente colocam esses sujeitos, de gêneros diferentes, em contextos opostos, numa separação clara entre o indivíduo e o social". Historicamente, a mulher, no universo religioso, sempre esteve em situação de submissão ao homem, ou sob ordem hierárquica do poder masculino.

A terceira questão foi: Porque a mulher da Congregação do Brasil não pode cortar o cabelo, usar maquiagem, usar joias e calças? Secamente respondeu a entrevistada 1: “a resposta está em 1 Pedro 3.3 -`Não seja o adorno da esposa o que é exterior, como frisado de cabelos, adereços de ouro, aparato de vestuário' e 1 Timóteo 2.9: - ‘Da mesma sorte, que as mulheres, em traje decente, se ataviem com modéstia e bom senso, não com cabeleira frisada e com ouro, ou pérolas, ou vestuário dispendioso'"' (Cf. entrevistada 1)

\footnotetext{
${ }^{8} \mathrm{https} / / /$ bereiano.wordpress.com/2011/04/28/fundamento-do-veu-r-cardoso/ Acessado em 12/05/2017.

9 Subjetividade como sendo, "um sistema complexo capaz de expressar através dos sentidos subjetivos a diversidade de aspectos objetivos da vida social que concorrem em sua formação". - (p. 19) 
Religare, ISSN: 19826605, v.15, n.2, dezembro de 2018, p.670-686.

$\mathrm{Na}$ linha dessas ideias, encontramos em Bourdieu (2003) uma explicação para o discurso religioso e suas implicações na subjetividade do ser. Para o autor o discurso religioso reproduz processos capazes de criar configurações e métodos, a partir do simbolismo explicito na comunicação do conhecimento. Isso, pode ser uma via/um meio de transformar as experiências particulares em atos pretensamente universais, que geralmente vem arraigados de preconceitos capazes de inferiorizar ou imobilizar outras experiências sociais.

Os resultados da pesquisa reiteram a ideia de que a percepção individual do mundo é influenciada pelo grupo. Isso pode ser observado mediante as falas das participantes desse estudo, retificando que aquilo que o grupo aprova ou valoriza tende a ser selecionado na percepção pessoal; já o que é rejeitado ou indiferente aos valores do grupo tem menor possibilidade de ser selecionado pela percepção do sujeito - e se for significativa para o sujeito, este o guarda para si ou o elabora de forma a adaptá-lo aos valores grupais, seja de foram lúdica, simbólica ou distorcida, no intuito de evitar a censura coletiva. ${ }^{10}$

\section{Resultados e discussão}

No cenário atual o multiculturalismo é visto como um estrado teórico e político que tenta apresentar respostas práticas a esse conturbado contexto social que é (in)diretamente influenciado pela diversidade cultural, esbarrando muitas vezes em situações de preconceito, discriminação e na difícil tarefa de se entender as inúmeras identidades que povoam os territórios plurais da sociedade contemporânea. Aprendemos, durante o processo de formação, que um desses territórios diversos e plurais é a escola

\footnotetext{
10 Sônia Regina Rocha Rodrigues, disponivel em http: / / www.qdivertido.com.br/verartigo.php?codigo=57, acessado em 15/05/2017.
} 
Religare, ISSN: 19826605, v.15, n.2, dezembro de 2018, p.670-686.

e seus contextos e aprendemos, enquanto professores, que é necessário e urgente dialogar acerca da educação intercultural, tendo em vista a pluralidade cultural existente nesse contexto.

A cultura é a lente pela e com a qual vemos o mundo, que inclui costumes, tradições e valores que corroboram para a construção da identidade dos indivíduos; por isso, o "fazer", "o expressar" e "o comportar-se " são, muitas vezes, traços e marcas indeléveis da cultura. Por isso, num território diverso e plural, temos que refletir acerca do preconceito e da intolerância que são observados em nosso meio e que podem aparecer em forma de humilhação "imposta para com aquele que é 'diferente'. [...] No momento em que alguém é humilhado, discriminado, agredido devido a sua cor ou a sua crença, ele tem seus direitos constitucionais, seus direitos humanos violados" (REZENDE JR, 2013, p.4).

A interculturalidade deve perpassar todos os âmbitos da sociedade, principalmente o currículo escolar que colabora com a formação integral do ser. A religiosidade deve ser problematizada pelos professores e demais autores do contexto da escola, considerando-se aí a diversidade religiosa, numa "interculturalidade religiosa, (esta) entendida como uma atividade que se vive e se estabelece não como mera transmissão de missão, mas como encontros de uma diversidade que se manifesta no espaço público ou em qualquer espaço". (REZENDE JR, 2013, p. 9).

\section{Conclusão}

O discurso religioso fundamenta-se na crença em um conteúdo revelado e preservado em escrituras com cunho sagrado. Nesse universo, as identidades de gênero, alinhadas ao discurso religioso, fundamentam-se do retorno ao passado, no intuito de buscar respostas que justifiquem as ações executadas no presente (HALL, 2006).

Essa pesquisa de cunho qualitativo teve o objetivo de refletir sobre os significados das práticas educativas depor professoras que são membros da 
Religare, ISSN: 19826605, v.15, n.2, dezembro de 2018, p.670-686.

Congregação Cristã do Brasil (CCB) quando essas envolvem temas que perpassam a religiosidade. Os dados possibilitaram sugerir que a cultura religiosa à qual as participantes estavam subordinadas é um dos elementos fundantes de suas identidades. Essa interpretação é pautada em quatro elementos: (i) a religião enquanto agente cultural, (ii) a religião enquanto fonte de propagação cultural, (iii) a religião como elemento de construção do espectador cultural e (iv) a religião e o alienado cultural. Talvez esses liames, que gravitam em torno da cultura, ajudem a explicar e compreender comportamentos sociais.

Ainda no eixo da educação, as participantes relataram a dificuldade em trabalhar a diversidade em sala de aula, principalmente quando estão em pauta questões ligadas às religiões afro, à sexualidade, às drogas e outros temas transversais. Assim, é importante uma abertura para a inclusão e a tolerância, calcadas no respeito à diferença e na dignidade da pessoa humana.

\section{Referências}

ALVEZ, J. Lindgren (2005) Os Direitos Humanos na Pós-Modernidade. São Paulo, Perspectiva.

Perspectiva.

(2003), Os Direitos Humanos como tema global. São Paulo: Ed.

BÍBLIA, Português. A Bíblia Sagrada: Antigo e Novo Testamento. Tradução de João Ferreira de Almeida. Edição rev. e atualizada no Brasil. Brasília: Sociedade Bíblia do Brasil, 1969.

BOURDIEU, Pierre. A Dominação Masculina. Rio de Janeiro: Bertrand Brasil, 1999.

BRASIL. Constituição. Constituição da República Federativa do Brasil. Brasília, DF: Senado Federal: Centro Gráfico, 1988.

. Lei 10.639/2003, de 9 de janeiro de 2003. Altera a Lei no 9. 394, de 20 de dezembro de 1996. Diário Oficial da União, Poder Executivo, Brasília, 2003. . Plano Nacional de Educação em Direitos Humanos. 4⿳a edição. Secretaria Especial dos Direitos Humanos, Presidência da República: Brasília, 2006.

- Secretaria de Educação Fundamental. Parâmetros Curriculares

Nacionais: terceiro e quarto ciclos: apresentação dos temas transversais. Brasília: MECSEF, 1998. 
Religare, ISSN: 19826605, v.15, n.2, dezembro de 2018, p.670-686.

CANDAU, Vera Maria. Direitos humanos, educação e interculturalidade: as tensões entre igualdade e diferença. Rev. Bras. Educ. [online]. 2008, vol.13, n.37, pp.45-56. http://dx.doi.org/10.1590/S1413-24782008000100005.

CECCHETTI, Elcio; OLIVEIRA, Lílian Blanck de. Diversidade religiosa e direitos humanos: conhecer, respeitar e conviver. Revista Interdisciplinar de Direitos Humanos,v. 3, $\quad$ n. $1, \quad 2015 . \quad$ Disponível em: http://www2.faac.unesp.br/ridh/index.php/ridh/article/view/268/129Acesso em: 20 maio 2017.

HALL, Stuart. A identidade cultural na pós modernidade. Trad. de Tomaz Tadeu da Silva e Guacira Lopes Louro. Rio de Janeiro: DP\&A, 2006.

JUNQUEIRA, Sérgio Rogério Azevedo; RODRIGUES, Edile Maria Fracaro. $A$ formação do professor de ensino religioso: o impacto sobre a identidade de um componente curricular. Pistis\&Praxis, Teol. Pastor, Curitiba, v. 6, n. 2, p. 587609, maio/ago. 2014. Disponível em: https://db.gper.com.br/nep/2014/09/0000002020-01-B4004238-PISTIS 12773.PDF Acesso em: 20 maio 2017

MILANI, NoeliZanatta. A escola a favor da diversidade religiosa: importância dessa abordagem em sala de aula. XI EDUCERE, Congresso Nacional de Educação, Pontifícia Universidade Católica de Paraná, Curitiba, 2013. Disponível em: http://educere.bruc.com.br/ANAIS2013/pdf/9410_4926.pdfAcesso em: 10 de jan. de 2018.

MINAYO, Maria Cecília de Souza. Ciência, técnica e arte: o desafio da pesquisa social. In: MINAYO, Maria Cecília de Souza (org.). Pesquisa Social. Teoria, método e criatividade. 18 ed. Petrópolis: Vozes, 2001.

REY, G. F. L. Sujeito e Subjetividade: uma aproximação histórico-cultural. São Paulo: Thomson Learning, 2003.

REZENDE JR, Jose. Diversidade religiosa e direitos humanos. Secretaria de Direitos Humanos da Presidência da República, Brasília, 2013. Disponível em: http://www.sdh.gov.br/assuntos/bibliotecavirtual/promocao-edefesa/publicacoes-2013/pdfs/diversidade-religiosa-e-direitos-humanos Acesso em: 20 maio 2017

SCOTT, Joan W. Preface a gender and politics of history. Cadernos Pagu, no . 3, Campinas/SP 1994.

VALENTE, Gabriela Abuhab. Laicidade, Ensino Religioso e religiosidade na escola pública brasileira: questionamentos e reflexões. Pro-Posições, Campinas , v. 29, n. 1, p. 107-127, Abr. 2018 . Disponível em: $<$ http://www.scielo.br/scielo.php?script=sci_arttext\&pid=S0103-

73072018000100107\&lng=en\&nrm=iso>. Acesso em: 29 abril 2018. http://dx.doi.org/10.1590/1980-6248-2016-0108

VALENTE, Gabriela Abuhab. Uma religiosidade na prática docente. Rev. Bras. Estud. Pedagog. Brasília, v. 98, n. 248, p. 198-211, janeiro de 2017. Disponível

em 
Religare, ISSN: 19826605, v.15, n.2, dezembro de 2018, p.670-686.

<http://www.scielo.br/scielo.php?script=sci_arttext\&pid=S2176668120170000 0198\&lng=en\&nrm=iso>. Acesso em: 10 de dezembro de 2017. http://dx.doi.org/10.24109/2176-6681.rbep.98i248.2874.

Recebido em 03-05-2018. Aprovado em 20-01-2019. 